\title{
A portrait of accessibility change for four US metropolitan areas
}

\author{
Louis A. Merlin \\ University of Michigan \\ louismerlin@gmail.com
}

\author{
Article history: \\ Received: January 16, 2015 \\ Received in revised form: \\ November 18, 2015 \\ Accepted: November 23, 2015 \\ Available online: June 17, 2016
} tions, changing employment locations, and changing travel speeds on accessibility change is decomposed and analyzed. Residential locations are generally shifting toward low-accessibility locations, degrading regional accessibility. Shifting employment locations have differential effects across metros, improving the accessibility of central locations in some metros while improving the accessibility of peripheral locations in others. Travel speeds also show strongly contrasting patterns across metros, with speed-related accessibility benefits concentrated in high-density locations for some metros (Chicago), while low-density locations are the primary beneficiary in other metros (Charlotte and St. Louis).

Keywords: Accessibility, infill, speed, metropolitan planning, congestion, travel-demand models

\section{Introduction}

Planners and planning researchers have been arguing for an increased focus on accessibility in evaluating the performance of urban transportation systems for several decades (Cervero 1996; Handy and Niemeier 1997; Geurs and Ritsema van Eck 2003; Grengs et al. 2010). Accessibility measures are rooted in the idea that transportation is a derived demand, i.e., that the primary purpose of the transportation system is to provide access to destinations of interest. One purpose of accessibility measures is to describe how much access to urban opportunity a household has from a particular residential or geographic location. As such, these measures take into account the number of urban opportunities available, the location of these opportunities relative to a household's residence, and the difficulty of reaching these opportunities in terms of travel time or costs. Accessibility measures can also take into account individual characteristics and temporal constraints (Miller 1999), but the focus on this particular paper is on geographic measures of accessibility as a performance metric for urban form. As an urban-

Copyright 2015 Louis A. Merlin

http://dx.doi.org/10.5198/jtlu/2015.808

ISSN: 1938-7849 | Licensed under the Creative Commons Attribution - Noncommercial License 3.0

The Journal of Transport and Land Use is the official journal of the World Society for Transport and Land Use (WSTLUR) and is published and sponsored by the University of Minnesota Center for Transportation Studies. 
form performance metric, accessibility metrics are able to account for the role both land-use patterns and transportation infrastructure play in providing transportation system benefits.

Higher accessibility has been most commonly associated with lower vehicle miles traveled (VMT) (Levinson 1998; Ewing and Cervero 2010), and while this is an important benefit of higher accessibility, it is by no means the only benefit. In addition to lower VMT, higher accessibility may allow households the opportunity to participate in more discretionary (non-work) activities given their household time budget constraints (Krizek 2003; Merlin 2014). In addition, there is an inherent value in the choices provided by an accessible location. For example, a person seeking dining options within a high-accessibility location is likely to enjoy a choice among many restaurants rather than just a few. Being proximate to multiple choices offers more discretion and greater freedom for households in conducting their daily activities. Accessibility can be used as a spatial measure for this increased scope of social and economic opportunity.

Innovative metropolitan planning organizations are increasingly making use of accessibility measures to evaluate alternative plans as part of region-wide scenario planning efforts. The Puget Sound Regional Council (PSRC) has been a leader in this regard, working with cumulative accessibility measures to various types of destinations by walking, by bicycling, and by transit in its most recent regional plan (Puget Sound Regional Council 2008). Accessibility measures are used by the PSRC to evaluate multiple long-range planning goals, including transportation, economic development, and environmental justice objectives. The Chicago Metropolitan Area for Planning has also employed similar accessibility metrics to evaluate regional scenarios for its "Go To 2040" Plan (Chicago Metropolitan Agency for Planning 2010). The Chicago Metropolitan Agency for Planning (CMAP) makes use of auto and transit-accessibility metrics to measure performance dimensions such as access to employment opportunity and environmental justice. There are also examples of accessibility measures being integrated into regional planning initiatives in Europe (Bertolini, le Clercq, and Kapoen 2005) and Australia (Curtis 2011), with one of the main purposes of accessibility-based thinking being the better integration of transportation and land-use planning. As accessibility thinking starts to permeate regional planning, assessing approaches for improving future accessibility at the metropolitan scale is becoming increasingly important.

To understand how transportation and land-use change influence metropolitan accessibility, planners must measure and track accessibility over time. Once accessibility is tracked over time, planners are better able to ascertain whether or not accessibility is improving, and how various land-use and transportation policies have influenced accessibility change across their metropolitan region. This paper provides an example of this type of analysis by tracking accessibility change over time for four metropolitan regions. The approach laid out in this paper is a potential template for regional planners to understand accessibility change within their own regions.

Proximity and speeds are the two underlying components of access to destinations as a geographic concept (Levine et al. 2012). In theory, if travel times do not change while land-use change results in increasing destination proximity, then such closer proximity would result in higher accessibility. Therefore, placing more residents in high-accessibility locations is one potential strategy for improving accessibility. Likewise, if travel times improve without any incidental changes to urban form, this would also result in increased accessibility. In principal, then, residential location and transportation improvements can be thought of as two potential policy levers for increasing spatial regional accessibility over time. The picture becomes more complex, of course, when feedback mechanisms between land use and transportation are considered, but conceptually it is helpful to consider and analyze the influence of land-use change and transportation change, each in isolation.

In recent decades, US metropolitan areas are likely to have become both lower in proximity due to 
urban expansion while also experiencing slower travel speeds due to rising congestion (Glaeser and Kahn 2003; Shrank, Lomax, and Eisele 2011; Weitz and Crawford 2012). If this is indeed the case, then many US metropolitan areas may be delivering less accessibility to many of their urban residents over time. That is, urban opportunities are becoming both farther away and more difficult to reach, on average, with negative repercussions for both households and the environment.

This paper examines how accessibility changed over a one-decade time span from 2000 to 2010 for four different major metropolitan areas. Whereas previous research has examined accessibility change over time for single metropolitan areas, or has compared the accessibility of multiple metropolitan areas at a single point in time, this is the first paper to examine in detail how accessibility changes over time across multiple metropolitan areas.

Changes to both land-use patterns and travel times vary significantly across the four metropolitan areas, suggesting that in addition to market factors, policy choices likely play a significant role in how accessibility changes over time. Both auto and transit modes are considered, making for some interesting contrasts with regard to how accessibility changes over time for each mode.

\subsection{Literature review: Accessibility change over time}

Accessibility can be measured many different ways and take into account several different dimensions; a complete review of the range and meaning of accessibility metrics is beyond the scope of this paper. Excellent reviews of the accessibility concept include Geurs and van Wee (2004), Bhat et. al. (2000), and Handy and Niemeier (1997). Geurs and van Wee, in particular, establish that accessibility measures should be sensitive to transportation changes, sensitive to land-use changes, sensitive to temporal constraints, and sensitive to individual needs and abilities. As the current paper focuses on analyzing urban-form change over time, the focus here is on transportation and land-use changes, while ignoring changes to temporal constraints and individual needs and abilities. The fact is that the built environment persists, while individuals' temporal constraints, abilities, and residential locations change more quickly over time. This is not to say that space-time accessibility analysis and individual accessibility analysis are not warranted. Implications of accessibility change for specific groups, in particular low-income groups, have become a growing and significant segment of the accessibility literature (Foth, Manaugh, and ElGeneidy 2013; Fan, Guthrie, and Levinson 2012; Grengs 2004). Also as new data sources and methods become available, the space-time accessibility research literature is blossoming as well (Owen and Levinson 2015; Neutens et al. 2012). The limited focus on the transportation and land-use dimensions in this paper is primarily for the purpose of establishing a clear baseline for understanding accessibility change with these simpler measures.

There is a large body of literature tracking accessibility changes over time and analyzing the spatial development effects of such accessibility changes. By far the bulk of this literature has occurred at the national or regional scale (Rosik, Stępniak, Komornicki 2015; Kim and Sultana 2015; Axhausen 2008), and most of it has been focused on the effects of major transportation improvements rather than population or land-use change (Holl 2007; Rosik, Stępniak, and Komornicki 2015; Shaw et al. 2014). Unsurprisingly, most of these papers find that major transportation improvements lead to major accessibility improvements along such corridors, but accessibility improvements often spill over geographically in surprising, complex, or unexpected ways (Stępniak and Rosik 2013; Gutierrez, Condeco-Melhorado, and Martin 2010; Chen, Claramunt, and Ray 2014). Still more complex are the effects of major transportation improvements on territorial cohesion or spatial equity, a major goal of both EU and national transport policy regimes. Some major transportation improvements, both roadway and railway, have resulted in greater territorial cohesion (Hou and Li 2011; Kim and Sultana 2015; ESPON 2013; Wang et al. 2009), while others have resulted in decreased or little change to territorial cohesion (Stępniak 
and Rosik 2015; Kim and Sultana 2015). Regardless of all such improvements, at the national scale, accessibility-dominant regions tend to maintain their dominance over very long periods of time, as far back as accurate transportation infrastructure data are available (i.e., back to the early 20th or mid-19th centuries (Axhausen, Froelich, and Tschoop 2011; Kim and Sultana 2015; Wang et al. 2009).

Separate analysis of land-use or population changes, as opposed to just transportation infrastructure changes, is much rarer, as is analysis at the metropolitan scale. The path-breaking works with regard to separating out the effects of land-use change on accessibility are Helling (1998), Cervero, Rood, and Appleyard (1999), Geurs and Ritsema Van Eck (2003) and Grengs (2004). Each of these is summarized briefly below.

Helling conducted an exposition of accessibility change in metropolitan Atlanta over the 1980 to 1990 period (Helling 1998). The study calculated accessibility to work by auto for each census tract. It separated out the effects of population patterns, employment patterns, and traffic congestion on accessibility change, finding that for this period, the effects of increased traffic congestion overwhelmed all other effects and resulted in reduced accessibility. However, one drawback of this analysis was that the study calculated a total regional rather than per capita accessibility, so the analysis did not illustrate the change in accessibility experienced by the average resident.

Cervero, Rood, and Appleyard (1999) tracked changes to work accessibility over time in the San Francisco Bay Area for the 1980 to 1990 period, breaking down their analysis by occupational grouping. The study used gravity accessibility measures, but was unable to distinguish auto and transit accessibility because its accessibility measures were based on highway distances rather than travel times. The study's approach emphasized the equity aspects of accessibility analysis, noting that accessibility increased for high-skill occupations while decreasing for lower-skill occupations in the Bay Area during the 1980 to 1990 period.

Geurs and van Eck (2003) examined accessibility change over time from 1995 to 2020 for the Netherlands, examining not historical accessibility change but forecast accessibility change based on modeled scenarios. The study employed such analysis in order to evaluate the accessibility impact of various potential regional land-use and transport policies. In addition to examining three different types of accessibility metrics (potential, Joseph and Bantock, inverse balancing factors), the study decomposes total accessibility change into a land-use component, a transport component, and a combination component. Furthermore, the research was able to separate out the transportation component into an infrastructure component and a congestion component. Geurs and van Eck found that, on average, the land-use changes increase accessibility, while congestion decreases accessibility over the period, with a net effect close to zero, though with significant spatial variation.

Grengs (2004) analyzes transit access to jobs for inner-city, low-income populations in the towns of Rochester and Buffalo, New York, between 1990 and 1997. By decomposing the effects of land-use change and transit separately, Grengs is able to find that these low-income populations saw increased accessibility during this time period, with the majority of the explanation being due to land-use changes, although improved transit services contributed to almost half of the accessibility improvement in Buffalo.

A few related works on metropolitan accessibility change over time have been published since this first wave. Levinson and Marion (2010) examined changes to accessibility to work by auto for Minneapolis from 1995 to 2005. Levinson and Marion employed cumulative accessibility measures based on a fixed commute time; these are more straightforward to compute than gravity measures, though they have some theoretical drawbacks due to the arbitrary nature of the cutoff point for such measures. Taking a geographical rather than household perspective, the study found that accessibility increased almost everywhere in the Minneapolis metropolitan region, and moreover that accessibility had increased more 
at the edge of the region than in its center. Accessibility increases occurred despite some increases to traffic congestion. In this case, the primary driver of the accessibility increase was metro-wide employment growth.

Levinson (2013) examined accessibility change over time from 1990 to 2010 for the 51 largest metropolitan areas of the United States using macroscopic data (i.e., urban-area scale measures of land use and transportation). Levinson found that accessibility growth tended to happen in fast-growing cities, while accessibility losses tended to happen in metros with serious congestion problems and/or population losses.

Martinez Sanches-Mateos et al. (2014) examined changes in cumulative opportunity, gravity potential, and competitive potential for municipalities around the Madrid region of Spain from 1981 to 2011. The research found that the region of high accessibility expanded outward from central Madrid and along several corridors toward secondary centers, contributing to a more polycentric structure for the Madrid region over time.

From these various longitudinal studies, it is difficult to make any generalizations about overall metropolitan accessibility trends. Metropolitan accessibility does seem to be spreading outward to encompass broader territories in both the United States and Europe (Martinez Sanchez-Mateos et al. 2014; Levinson and Marion 2010; Helling 1998), but whether or not that leaves the average household in a higher or lower accessibility situation is unclear. It does seem that employment growth, simply by increasing the number of work destinations available, is likely to increase accessibility to jobs for fast-growing metropolitan regions. Helling (1998) and Levinson (2013), which found severe effects of transportation congestion, suggest that slower travel times may also potentially have a large effect in reducing accessibility over time. Both Helling and Cervero suggest that changes to accessibility over time may vary significantly across the population groups. This paper builds on this previous work by describing longitudinal accessibility change for multiple metropolitan areas within a constant evaluation framework. For each metropolitan area, the influence of residential location changes, employment location changes, and travel times on accessibility change are separated and analyzed for their impacts on total accessibility change.

\section{Data and methods}

The four metropolitan areas of Charlotte, Chicago, St. Louis, and Seattle were selected to represent a diversity of conditions. Seattle and Charlotte experienced relatively strong metropolitan population growth during the study period, whereas Chicago and St. Louis did not. Chicago contrasts with St. Louis in that Chicago has an economically strong central city, whereas St. Louis does not. Both Seattle and Charlotte have pursued various smart-growth agendas, but Seattle's growth management framework is considerably more powerful, backed by state-level smart-growth legislation (Weitz 2012).

In addition, the metro areas were selected to have contrasting patterns with respect to traffic congestion, based on data from the Texas Transportation Institute's Urban Mobility Report (Shrank, Lomax, and Eisele 2011). The selection analysis was based on using total delay and total population from the Texas Transportation Institute's report for years 2000 and 2010 for the top 101 urban areas. Metropoli$\tan$ areas with the greatest percent increase and greatest percent decrease in delay per capita between 2000 and 2010 were identified. Presumably metros with increasing delay per capita experienced slowing auto travel speeds, whereas those with decreasing delay per capita experienced increasing travel speeds. However, the findings of this paper with respect to speed were not in alignment with the Texas Transportation Institute data ${ }^{1}$ (See section 3.4, "Effect of changing travel times," for a more detailed discussion of these results).

${ }^{1}$ It is debatable which data are more accurate with respect to travel speeds, Texas Transportation Institute (TTI) data based on traffic counts or the data I collected from metropolitan planning organizations. The TTI data are gathered on a national basis, and so there is less attention to potential variations in regional data. Also, the TTI data have varied methodologically over time. The travel-time data in this paper are based on regional travel-demand models, rather than observed data. However, the metropolitan planning organizations ran the same models on 2000 and 2010 data presumably making the speed data comparable over time. 
The four metropolitan areas selected represent contrasts more than similarities. Two metros are aging cities from the Midwest, and two are newer, faster growing cities from the West and South. Chicago stands out in particular as a metropolitan area with a significant legacy of transit use and an influential central city in terms of employment concentrations and commuting patterns. The transportation investment policies across these four metropolitan regions also present marked contrasts. Charlotte is notable for a commitment to a "five transit corridor" plan for its land-use and transportation investment strategy. This transit-focused strategy has been funded by a dedicated sales tax since 1998 (Mecklenberg/ Union Technical Cooridnating Committeee 2002). Seattle's long-range transportation plan (LRTP) from the year 2001, Destination 2030, emphasized how transportation investments should reinforce the metropolitan area's regional growth plan, Vision 2020. This regional growth plan encouraged channeling growth into existing urban centers (Puget Sound Regional Council and Council 2001). Chicago's and St. Louis' long-range transportation plans are notable for their emphasis on repairing existing infrastructure first: 71.6 percent of the East West Gateway's LRTP budget and 80.5 percent of the Chicago Area Transportation Study's budget are allocated to system maintenance, preservation, and restoration (East West Gateway Coordinating Council 2002; Chicago Area Transportation Study 2000). St. Louis' LRTP also mentions that the transit operator for the region, the Bi-State Development Agency, experienced unexpected operating budget deficits that resulted in service reductions in 2001; however, data from the National Transit Database show no decline in vehicle hours of transit service for St. Louis for the 2000 to 2010 period (Table 1). Each of the metropolitan areas selected is changing under the influence of distinctive circumstantial and policy forces that have shaped their urban forms (proximity) and their transportation systems (speeds).

Table 1: Demographic and transportation statistics for four metros, 2000-2010

\begin{tabular}{lcccc}
\hline & Seattle & Charlotte & St. Louis & Chicago \\
\hline Population 2000 (1000s) & 2914 & 1183 & 2300 & 8821 \\
Population 2010 (1000s) & 3337 & 1612 & 2416 & 9198 \\
Population growth & $14.5 \%$ & $36.2 \%$ & $5.1 \%$ & $4.3 \%$ \\
& & & & \\
Employment 2000 (1000s) & 1647 & 767 & 1338 & 4571 \\
Employment 2010 (1000s) & 1641 & 808 & 1287 & 4247 \\
Employment growth & $-0.3 \%$ & $5.3 \%$ & $-3.8 \%$ & $-7.1 \%$ \\
& & & & $11.5 \%$ \\
Transit commute mode share 2000 & $6.8 \%$ & $1.4 \%$ & $2.4 \%$ & $11.2 \%$ \\
Transit commute mode share 2010 & $8.2 \%$ & $2.0 \%$ & $2.6 \%$ & $-0.3 \%$ \\
Change in transit mode share & $1.4 \%$ & $0.6 \%$ & $0.2 \%$ & $10,882,811$ \\
& & & & $10,832,683$ \\
Transit vehicle hours of service 2000 & $3,812,586$ & 765,554 & $1,517,225$ & $-0.5 \%$ \\
Transit vehicle hours of service 2010 & $4,867,259$ & 991,558 & $1,692,380$ & $11.5 \%$ \\
Change in transit vehicle hours & $27.7 \%$ & $29.5 \%$ & & \\
\hline
\end{tabular}

Source: US Census 2000; US Census 2010; Bureau of Labor Statistics, 2013; National Transit Database, 2013

\subsection{Components of spatial accessibility change: Household locations, employment locations, and travel time change}

Accessibility to jobs is used here as a general proxy for ease of access to urban opportunities, both for work opportunities and non-work opportunities (Helling 1998; Ahlfeldt 2011). Helling and Ahlfeldt have also argued for accessibility to jobs to be considered a general measure of urban opportunity: Ahlfeldt said, "Given that employment within the city is likely to be correlated with various urban economic activities, for example, shopping or entertainment opportunities, [job accessibility] qualifies as an 
index of urban centrality in a broader sense." Although most workers only commute to one job, a large percentage of non-work travel is to destinations where other people are working-e.g., retail workers at shops, medical workers at doctor's offices, education workers at schools, etc. Although not all jobs are in fact equally suitable proxies for indicating the location of urban opportunity, when examining a broad range of access at the regional scale, measures of access to all types of jobs from one's residential location provides a reasonable benchmark for generalized access to urban opportunity.

Gravity (or potential) accessibility measures are employed to assess residents' accessibility from their home location (Equation 1). One advantage of gravity accessibility measures is that they take into account opportunities available anywhere in the metropolitan region, while discounting those opportunities by factoring in the difficulty of reaching them through measures of travel time or cost. Households are assigned an accessibility score based on accessibility to all types of employment from their home traffic analysis zone, or TAZ. The standard gravity accessibility formula is implemented, travel time used to estimate generalized travel costs. Separate accessibility measures are calculated for auto and transit modes:

$A_{i}=\sum_{j=i}^{n} O_{j} e^{-\delta^{2} i}$

Where $A_{i}$ is the accessibility at TAZ $i, O_{j}$ is the number of opportunities (total employment) available in TAZ $j$, $\delta$ is the impedance coefficient for travel time, and $t_{i j}$ is the travel time from TAZ $i$ to TAZ $j$ in minutes.

Spatial accessibility change over time is influenced by three factors: changing locations of residences; changing locations of opportunities (in this case jobs); and changing travel times (See Figure 1 below). If population and housing growth are concentrated in lower accessibility parts of the region, then the average (median or mean) accessibility for households will decrease. Employment growth, on the other hand, increases accessibility for all households, simply by increasing the number of available destinations. (Likewise, employment losses result in decreased accessibility for all households.) However, if total employment is held constant, then the changing locations of employment can influence which residential locations experience accessibility improvement and which experience accessibility declines. As the balance of employment shifts locations across the region, those areas that become more proximate to employment see accessibility benefits, while those that become less proximate experience an accessibility decrease (holding other factors constant). Finally, changing travel times influence accessibility from a given residential location. If travel times are faster, all other aspects held constant, accessibility increases, whereas if travel times are slower, accessibility decreases from a particular location.

There are also interaction effects between each of these pairs of changes. For example, if residential growth happens in the same location as travel-cost improvements, there is the potential for synergistic improvements. However, from a practical point of view, these interaction effects are typically small. Analysis conducted herein suggests that total accessibility change is nearly equal to the sum of the three effects outlined above, a finding also confirmed in Geurs and Ritsema van Eck (2003).

Taken together we have a complex portrait of accessibility change for each region-for each location, accessibility may be going up or down because of changing travel times and new employment destinations, while at the same time, shifts in the residential population alter how many households live in relatively high-accessibility or low-accessibility locations. In this paper, each of these components of accessibility change is presented individually to help researchers and planners gain insight into the multidimensional dynamics of accessibility change and into the interactions of transportation/land-use relationships in particular. 


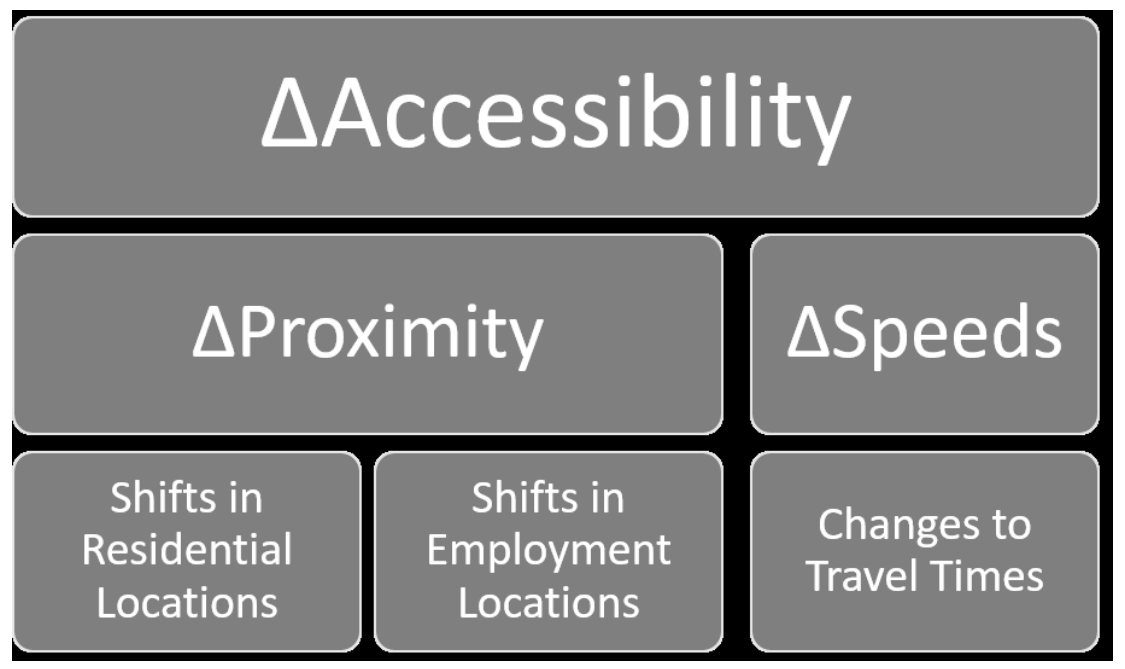

Figure 1: Components of urban form accessibility change

To examine the influence of changing residential locations, household growth is examined by quintile of year 2000 accessibility. If more household growth is occurring in high-accessibility areas, this will contribute to overall higher household accessibility at the metro scale. Note that this approach holds travel speeds and employment locations fixed in order to focus exclusively on the impact of shifts in residential location.

Next, the analysis focuses on the effect of changing employment locations. Accessibility variations resulting from shifting employment locations are examined by quintile of year 2000 accessibility. For this part of the analysis, residential locations and speeds are held constant. In addition, total employment levels are also held constant, so that employment growth has no effect. The results, therefore, reflect the effects of shifting the pattern of employment locations only. Some researchers have speculated that employment decentralization is particularly helpful to households in low-accessibility parts of the region (Giuliano and Small 1993; Cervero and Wu 1998). If so, this should be apparent at this stage of the analysis by revealing a greater increase in accessibility for lower-accessibility parts of the metropolitan regions.

Finally, the analysis presents the influence of changing travel speeds. Changes to accessibility are calculated by varying travel speeds between zones from their 2000 to their 2010 levels while holding population and employment locations constant. This allows the analysis to isolate the influence of changes to the transportation system alone. These changes to accessibility are presented across quintiles of household density and via a series of maps illustrating the effect of speed changes on accessibility. These tables and maps illustrate whether improvements to travel speeds are targeted toward more densely settled areas, or whether they are more targeted toward less densely settled, predominantly undeveloped areas.

\subsection{Data sources}

To understand the dynamics of accessibility change, data are needed on residential and employment counts for TAZs. Housing totals were used to estimate residential locations. Although housing totals do not always equate with population, housing units represent durable investments in residential locations. Metropolitan planning organizations provided housing counts by travel analysis zone for the two time periods, 2000 and 2010.

Employment locations were also taken from metropolitan planning organization data for both 
time periods. These data describe the physical distribution of jobs throughout each metro area. The Puget Sound Regional Council was unable to provide employment counts for the year 2000 due to privacy constraints; however, these counts were obtained from the Census Transportation Planning Package for the year 2000 (Bureau of Transportation Statistics 2004).

For metropolitan St. Louis, travel model information was only available back to the year 2002, and therefore 2002 population and employment counts were used as the baseline year as opposed to year 2000.

Metropolitan planning organizations (MPOs) also provided travel times by auto and by transit modes between all pairs of TAZs for the two years under analysis. In some cases, MPOs "backcasted" their current transportation model to derive travel times based on historical transportation networks and historical population and employment patterns.

MPOs differ in how they categorize travel times by mode and by time of day. Some MPOs detail multiple transit modes and multiple mechanisms for reaching transit, i.e., walked to transit, drove to transit, etc. To calculate a single transit travel time for each MPO, the fastest transit travel time was selected for each TAZ-to-TAZ pair. Also, it was assumed that the mode for transit access was walking. Where MPOs had available estimates of walk-to-transit travel times, these were used; otherwise walking time to transit was estimated based on TAZ land area. Congested or morning travel times were used for calculating all accessibility measures.

For each metro area, a computation of intra-zonal travel time was also necessary, because residents of each TAZ also have access to destinations within their home TAZ. Intra-zonal travel times were estimated as one-half of the average travel time to the three closest TAZs, computed separately by mode.

The impedance coefficient for travel time is assumed to be constant and based on the metropolitan area size, with larger metropolitan areas having smaller impedances. Identical impedances are used for transit and auto accessibility calculations. Impedance coefficients are used for the purpose of weighting the attractiveness of opportunities based on how long it takes to reach them (Equation 1). More specifically, travel time impedance is estimated based on metro population size through the formula below (Equation 2) (Levine, Grengs, and Shen 2010). A sensitivity analysis was conducted on these impedance coefficients, finding that altering the impedance coefficient upward or downward by 20 percent results in accessibility measures that are nearly identical with those used in this analysis (correlated at 0.98 or higher). See the appendix for a further discussion of the sensitivity analysis.

$\delta=0.109^{*} \exp \left(-3.53 * 10^{-8} *\right.$ metro.population $)$

Table 2 shows the specific impedances used to calculate accessibility scores for each metropolitan area.

Table 2: Impedance coefficients for calculating accessibility

\begin{tabular}{lcc}
\hline Metro Area & Impedance & Metro Population (millions) \\
\hline Chicago & 0.078 & 10.33 \\
Seattle & 0.097 & 3.70 \\
St. Louis & 0.100 & 2.57 \\
Charlotte & 0.103 & 2.22 \\
\hline
\end{tabular}

Note: Impedances are calculated in units of minutes ${ }^{-1}$. Impedances are assumed to be constant across each metropolitan area and for the two years under analysis in order to compare the two years on An equivalent basis. See the appendix for a sensitivity analysis of accessibility calculations with varying impedance coefficients. 
A smaller impedance coefficient suggests a willingness to travel a longer time to reach opportunities. Larger metro areas have smaller impedances for two reasons: first, they offer a greater range of opportunities, and therefore offer a greater incentive to travel longer distances; and second, they have higher levels of traffic congestion, and therefore residents become more accustomed to dealing with longer travel times.

Impedance coefficients are held constant over time for each metropolitan area in order to make accessibility measures comparable over time (Grengs 2010, Condeco-Meholrado and Martin 2010). However, since different impedance coefficients are used for each metropolitan area, the accessibility scores are not directly comparable between metropolitan areas. In addition, different MPO travel models make it so that travel times, and in particular transit travel times, also are not readily comparable across metros.

\section{Results: Changing metropolitan accessibility}

\subsection{Total accessibility change for the metropolitan populations}

Total accessibility change reflects the aggregate impact of changes in residential patterns, changes in employment patterns, and changes in travel times. These results are displayed by accessibility quantile for auto and accessibility tercile for transit, along with the decomposition of these changes into their component effects in Table 3 and Table 4. Two kinds of effects can be discerned for each metro-component pairing. In some cases, change in the underlying component results in a fairly uniform change across the given metro area-for example, employment shifts have a small positive effect across all five Chicago quintiles. In other cases, there is a clear trend across the quintiles, likely representing differential spatial effects; these are highlighted via a box around the component effects. Some examples of this are changes due to auto travel times in Chicago, which are positive for the top quintiles but negative for the bottom quintiles; or changes due to employment shifts in Seattle, which are positive for the top quintiles but negative for the bottom quintiles. These differential shifts are explored in greater detail in later tables and figures within the Results section. Note that residential shifts tend to have negative impacts across the board for auto accessibility. Employment shifts have varying effects by metro. Travel-time shifts exhibit fairly strong differential effects for each metro, a facet explored in more detail in Tables 11-15.

Transit exhibits more differential shifts due to land-use changes but more uniform shifts due to transit travel-time changes. Positive shifts in the top transit tercile due to residential and employment pattern changes may reflect the benefits of transit-oriented developments. Overall improvement in transit accessibility for the top tercile is noticeable in Charlotte, Chicago, and Seattle, all of which have improvements of over 10 percent. St. Louis underwent dramatic decreases in transit accessibility across the board, primarily due to decreased transit service (further discussed in the "Effect of changing travel times" section that follows) $)^{2}$.

\footnotetext{
2 The losses in transit accessibility due to declining transit service in St. Louis from 2002 to 2010 were larger than expected, on the order of 60 percent. However, the decline in transit service during 2009 to 2010 was confirmed in discussions with the East West Council of Governments staff. Voters rejected a countywide sales tax to fund public transit (Proposition M) in 2008, and in the aftermath, there was a funding shortfall and a resultant dramatic reduction in transit service. Later in 2010, another tax to support public transit was offered and this one passed, Proposition A. In the ensuing years, public transit service was reestablished to its former levels (Swanstorm et al. 2011).
} 
One way to analyze the relative investment in transit versus auto modes is to examine the ratio of transit to auto accessibility for particular geographies and track how this ratio changes over time. The ratio of transit to auto accessibility cannot meaningfully be compared across metros, however, because the modeling methods for calculating transit travel times vary substantially. Table 5 shows that both Chicago and St. Louis experienced decreases in the percent of households with high transit/auto accessibility ratios between 2000 and 2010, suggesting higher priority to auto relative to transit mode during this period. Seattle, on the other hand, displays increasing numbers of households with high transit/auto accessibility ratios between 2000 and 2010. Charlotte's travel model produces unusually high walk-totransit travel times, and so no households appear to exceed the 10 percent ratio threshold, although in reality Charlotte's transit accessibility is not necessarily lower than the other metros analyzed.

Table 3: Total auto accessibility change by component by quintile

\begin{tabular}{|c|c|c|c|c|c|c|}
\hline Metro & $\begin{array}{l}\text { Auto Accessibility } \\
\text { Quintile }\end{array}$ & $\begin{array}{l}\% \text { Change due to } \\
\text { Residential Shifts }\end{array}$ & $\begin{array}{l}\% \text { Change due to } \\
\text { Employment Shifts }\end{array}$ & $\begin{array}{l}\% \text { Change due to } \\
\text { Travel Time Shifts }\end{array}$ & $\begin{array}{c}\% \text { Change } \\
\text { due to } \\
\text { Interactions }\end{array}$ & $\begin{array}{l}\text { Total \% } \\
\text { Change }\end{array}$ \\
\hline \multirow[t]{5}{*}{ Charlotte } & Highest quintile & $-3.3 \%$ & $0.6 \%$ & $-1.2 \%$ & $0.2 \%$ & $-3.7 \%$ \\
\hline & 2nd quintile & $-4.1 \%$ & $2.2 \%$ & $9.8 \%$ & $1.1 \%$ & $9.2 \%$ \\
\hline & 3rd quintile & $-0.2 \%$ & $0.2 \%$ & $17.3 \%$ & $0.5 \%$ & $17.8 \%$ \\
\hline & 4th quintile & $2.7 \%$ & $-0.6 \%$ & $13.8 \%$ & $2.8 \%$ & $18.7 \%$ \\
\hline & Lowest quintile & $6.0 \%$ & $-5.2 \%$ & $6.1 \%$ & $2.3 \%$ & $9.1 \%$ \\
\hline \multirow[t]{5}{*}{ Chicago } & Highest quintile & $-0.2 \%$ & $3.8 \%$ & $15.7 \%$ & $-4.5 \%$ & $14.8 \%$ \\
\hline & 2nd quintile & $-4.3 \%$ & $2.5 \%$ & $23.6 \%$ & $-7.8 \%$ & $14.0 \%$ \\
\hline & 3rd quintile & $-8.9 \%$ & $0.8 \%$ & $22.1 \%$ & $-9.7 \%$ & $4.4 \%$ \\
\hline & 4th quintile & $-14.9 \%$ & $3.2 \%$ & $-1.9 \%$ & $-4.3 \%$ & $-18.0 \%$ \\
\hline & Lowest quintile & $-8.6 \%$ & $2.7 \%$ & $-10.1 \%$ & $-0.9 \%$ & $-16.9 \%$ \\
\hline \multirow[t]{5}{*}{ St. Louis } & Highest quintile & $-0.7 \%$ & $-6.5 \%$ & $2.8 \%$ & $0.0 \%$ & $-4.4 \%$ \\
\hline & 2nd quintile & $-5.0 \%$ & $-4.0 \%$ & $2.9 \%$ & $0.7 \%$ & $-5.4 \%$ \\
\hline & 3rd quintile & $-9.3 \%$ & $-0.7 \%$ & $8.8 \%$ & $1.5 \%$ & $0.2 \%$ \\
\hline & 4th quintile & $-8.0 \%$ & $4.0 \%$ & $8.9 \%$ & $-2.7 \%$ & $2.2 \%$ \\
\hline & Lowest quintile & $-7.3 \%$ & $4.4 \%$ & $8.5 \%$ & $-1.1 \%$ & $4.4 \%$ \\
\hline \multirow[t]{5}{*}{ Seattle } & Highest quintile & $-1.0 \%$ & $6.8 \%$ & $-1.8 \%$ & $-0.3 \%$ & $3.7 \%$ \\
\hline & 2nd quintile & $-4.7 \%$ & $3.7 \%$ & $-3.5 \%$ & $-1.0 \%$ & $-5.5 \%$ \\
\hline & 3rd quintile & $-3.9 \%$ & $-3.0 \%$ & $-4.2 \%$ & $-0.4 \%$ & $-11.5 \%$ \\
\hline & 4th quintile & $-7.1 \%$ & $-5.6 \%$ & $-5.3 \%$ & $0.3 \%$ & $-17.7 \%$ \\
\hline & Lowest quintile & $-3.5 \%$ & $-10.5 \%$ & $-8.5 \%$ & $0.3 \%$ & $-22.2 \%$ \\
\hline
\end{tabular}

Note: This table illustrates change in quintiles of auto accessibility due to residential shifts, employment shifts, travel-time shifts, and interaction effects. Boxes indicate differential trends across quintiles, which suggest differential spatial impacts. These differential spatial impacts are explored further in Tables 6, 9, and 13 and in Figures 2 and 3. 
Table 4: Total transit accessibility change by component by tercile

\begin{tabular}{|c|c|c|c|c|c|c|}
\hline Metro & $\begin{array}{c}\text { Transit } \\
\text { Accessibility } \\
\text { Tercile } \\
\end{array}$ & $\begin{array}{l}\% \text { Change due to } \\
\text { Residential Shifts }\end{array}$ & $\begin{array}{l}\text { \% Change due to } \\
\text { Employment Shifts }\end{array}$ & $\begin{array}{l}\% \text { Change due to } \\
\text { Travel Time Shifts }\end{array}$ & $\begin{array}{c}\% \text { Change } \\
\text { due to } \\
\text { Interactions }\end{array}$ & $\begin{array}{l}\text { Total \% } \\
\text { Change }\end{array}$ \\
\hline Charlotte & $\begin{array}{l}\text { Highest tercile } \\
\text { 2nd tercile } \\
\text { Lowest tercile }\end{array}$ & $\begin{array}{c}7.8 \% \\
-13.1 \% \\
-13.2 \% \\
\end{array}$ & $\begin{array}{r}1.6 \% \\
-4.6 \% \\
-5.4 \% \\
\end{array}$ & $\begin{array}{c}9.6 \% \\
8.2 \% \\
14.3 \%\end{array}$ & $\begin{array}{l}8.0 \% \\
8.4 \% \\
5.2 \%\end{array}$ & $\begin{array}{c}27.0 \% \\
-1.2 \% \\
0.9 \% \\
\end{array}$ \\
\hline Chicago & $\begin{array}{l}\text { Highest tercile } \\
\text { 2nd tercile } \\
\text { Lowest tercile }\end{array}$ & $\begin{array}{c}2.3 \% \\
-13.9 \% \\
-20.0 \% \\
\end{array}$ & $\begin{array}{l}25.5 \% \\
15.2 \% \\
10.2 \% \\
\end{array}$ & $\begin{array}{c}-14.1 \% \\
-11.7 \% \\
9.9 \% \\
\end{array}$ & $\begin{array}{c}-1.7 \% \\
1.1 \% \\
1.9 \%\end{array}$ & $\begin{array}{c}12.0 \% \\
-9.3 \% \\
2.0 \%\end{array}$ \\
\hline St. Louis & $\begin{array}{l}\text { Highest tercile } \\
\text { 2nd tercile } \\
\text { Lowest tercile }\end{array}$ & $\begin{array}{l}0.8 \% \\
-2.1 \% \\
-4.0 \%\end{array}$ & $\begin{array}{c}-13.0 \% \\
-7.4 \% \\
-4.9 \% \\
\end{array}$ & $\begin{array}{l}-59.5 \% \\
-62.3 \% \\
-63.0 \%\end{array}$ & $\begin{array}{l}7.4 \% \\
5.5 \% \\
5.5 \%\end{array}$ & $\begin{array}{l}-64.2 \% \\
-66.4 \% \\
-66.4 \%\end{array}$ \\
\hline Seattle & $\begin{array}{l}\text { Highest tercile } \\
\text { 2nd tercile } \\
\text { Lowest tercile }\end{array}$ & $\begin{array}{l}0.7 \% \\
-7.8 \% \\
-8.1 \% \\
\end{array}$ & $\begin{array}{r}9.1 \% \\
-4.8 \% \\
-16.3 \% \\
\end{array}$ & $\begin{array}{c}9.9 \% \\
13.4 \% \\
13.9 \% \\
\end{array}$ & $\begin{array}{r}1.5 \% \\
-1.3 \% \\
-3.3 \% \\
\end{array}$ & $\begin{array}{c}21.1 \% \\
-0.4 \% \\
-13.8 \% \\
\end{array}$ \\
\hline
\end{tabular}

Note: This table illustrates change in terciles of transit accessibility due to residential shifts, employment shifts, travel-time shifts, and interaction effects. Populations with zero transit accessibility in year 2000 are excluded. Boxes indicate differential trends across quintiles, which suggest differential spatial impacts. These differential spatial impacts are explored further in Tables 7 , 10, and 14 and in Figures 4 and 5.

Table 5: Percent of households exceeding given transit/auto accessibility ratios

\begin{tabular}{cccccc}
\hline \multirow{2}{*}{2000} & & Charlotte & Chicago & St. Louis & Seattle \\
\hline \multirow{2}{*}{2010} & Exceeding 10\% & $0 \%$ & $29.1 \%$ & $43.2 \%$ & $19.6 \%$ \\
& Exceeding 20\% & $0 \%$ & $8.8 \%$ & $24.8 \%$ & $5.0 \%$ \\
& & & & & \\
& Exceeding 10\% & $0 \%$ & $19.6 \%$ & $14.4 \%$ & $23.9 \%$ \\
& Exceeding 20\% & $0 \%$ & $4.4 \%$ & $1.0 \%$ & $7.3 \%$ \\
\hline
\end{tabular}

Note: This table shows the percent of households that exceeds a given transit accessibility/auto accessibility ratio for a given year, assuming the same travel time impedance coefficient for both modes. Charlotte's values are all zero because Charlotte's travel model assumes high walk-to-transit travel times.

Table 6: Household growth by auto accessibility quintile

\begin{tabular}{lccccccccc}
\hline & \multicolumn{3}{c}{ Percent Growth in Households, 2000 - 2010 } & \multicolumn{3}{c}{ Housing Units per Hectare (Per Acre) } \\
\hline $\begin{array}{l}\text { Auto Accessibility } \\
\text { 2000 Quintiles }\end{array}$ & Charlotte & Chicago & St. Louis & Seattle & Charlotte & Chicago & St. Louis & Seattle \\
Highest quintile & $25.0 \%$ & $2.7 \%$ & $-3.8 \%$ & $9.1 \%$ & $2.72(1.10)$ & $8.35(3.38)$ & $6.78(2.74)$ & $7.81(3.16)$ \\
2nd quintile & $40.0 \%$ & $-1.0 \%$ & $-3.7 \%$ & $7.2 \%$ & $1.88(0.76)$ & $8.96(3.63)$ & $4.61(1.87)$ & $4.07(1.65)$ \\
3rd quintile & $40.3 \%$ & $-0.7 \%$ & $0.8 \%$ & $15.2 \%$ & $1.21(0.49)$ & $5.66(2.29)$ & $2.67(1.08)$ & $3.73(1.51)$ \\
4th quintile & $42.2 \%$ & $13.5 \%$ & $11.6 \%$ & $18.8 \%$ & $0.55(0.22)$ & $2.20(0.89)$ & $1.46(0.59)$ & $1.99(0.81)$ \\
Lowest quintile & $24.4 \%$ & $21.3 \%$ & $15.1 \%$ & $22.7 \%$ & $0.20(0.08)$ & $0.33(0.13)$ & $0.22(0.09)$ & $0.17(0.07)$ \\
\hline
\end{tabular}

Note: Traffic analysis zones are sorted by auto accessibility scores for the year 2000 from highest to lowest, and then divided into five equal population areas. Therefore each quintile represents 20 percent of the metropolitan population, but varying amounts of land area. 


\subsection{Effect of changing residential locations}

Household growth was strongly focused in low auto accessibility areas for Chicago, St. Louis, and Seattle. Table 6 illustrates how household growth varies differentially for high-accessibility and low-accessibility parts of each metropolitan region. For Charlotte, the middle three quintiles all experienced strong household growth of around 40 percent from 2000 to 2010. St. Louis saw population declines in its top two most accessible quintiles, while Chicago underwent weak growth (2.7 percent) in its most accessible quintile, much lower than the strong growth in its lowest accessibility quintile (21.3 percent). Seattle experienced modest household growth in its top two quintiles, but much less growth than the bottom two. Altogether residential locations shifted toward lower-accessibility areas for three of these four metros, and even in Charlotte high-accessibility areas were not favored over low-accessibility ones with respect to household growth.

Table 8 confirms these results. There is a statistically significant negative correlation between household growth during 2000 and 2010 and auto accessibility in the year 2000 for Chicago, St. Louis, and Seattle, and no significant positive correlation of household growth with auto accessibility in Charlotte.

Transit accessibility shows similar trends, as illustrated by Table 7, which shows how household growth varies by level of transit accessibility. The highest rates of household growth across all four metros were in areas with zero transit access. As the level of transit accessibility increases, the level of household growth declines correspondingly for all four metros.

Table 7: Household growth by transit accessibility tercile

\begin{tabular}{lcccccccc}
\hline & \multicolumn{3}{c}{ Percent Growth in Households, 2000 - 2010 } & \multicolumn{4}{c}{ Percent of Population } \\
\hline $\begin{array}{l}\text { Transit Accessibility } \\
\text { 2000 Terciles }\end{array}$ & Charlotte & Chicago & St. Louis & Seattle & Charlotte & Chicago & St. Louis & Seattle \\
Highest tercile & $16.9 \%$ & $0.1 \%$ & $-4.2 \%$ & $9.3 \%$ & $15.4 \%$ & $30.4 \%$ & $18.0 \%$ & $33.3 \%$ \\
2nd tercile & $20.2 \%$ & $-0.5 \%$ & $-4.1 \%$ & $11.7 \%$ & $15.2 \%$ & $30.5 \%$ & $18.1 \%$ & $33.5 \%$ \\
3rd tercile & $31.2 \%$ & $18.1 \%$ & $0.4 \%$ & $22.8 \%$ & $15.2 \%$ & $30.4 \%$ & $17.8 \%$ & $33.2 \%$ \\
No transit & $44.2 \%$ & $20.6 \%$ & $11.7 \%$ & $28.6 \%$ & $54.2 \%$ & $8.7 \%$ & $46.2 \%$ & $0.1 \%$ \\
accessibility & & & & & & & & \\
\hline
\end{tabular}

Note: Traffic analysis zones are sorted by transit accessibility scores from highest to lowest. Areas with zero transit accessibility in 2000 are handled as a separate category. Traffic analysis zones with positive transit accessibility are divided into three equal population areas. Therefore, each tercile represents roughly 33 percent of the metropolitan population in areas with transit access.

Table 8: Correlation between household growth and auto accessibility

\begin{tabular}{lcccc}
\hline \multicolumn{2}{l}{ Correlation between Percent Household Growth from 2000-2010 and Year 2000 Auto Accessibility } \\
& Charlotte & Chicago & St. Louis & Seattle \\
\hline Correlation & 0.004 & -0.120 & -0.192 & -0.281 \\
T statistic & 0.197 & -5.317 & -9.822 & -8.950 \\
P statistic & 0.844 & 0.000 & 0.000 & 0.000 \\
N & 2934 & 1944 & 2527 & 938 \\
\hline
\end{tabular}

Note: Unit of analysis is the traffic analysis zone. 


\subsection{Effect of changing employment locations}

Changes to employment locations and total numbers of employment also influence accessibility over time. Table 9 shows the effect of shifting employment locations on auto accessibility, while Table 10 shows the effects on transit accessibility. Previous research on employment decentralization suggests that it may benefit residents of outlying areas by increasing their accessibility to work places (Giuliano and Small 1991; Giuliano and Small 1993; Cervero and Wu 1998; Glaeser and Kahn 2003). At the same time, of course, employment decentralization decreases the employment accessibility of center city residents, particularly those who are transit dependent.

St. Louis and Chicago experienced increased auto accessibility due to employment decentralization for their lowest accessibility quintiles. St. Louis also saw a decline in employment accessibility for its highest accessibility areas, while in contrast Chicago experienced modest improvements. Metro Seattle underwent the strongest trend toward employment centralization, with accessibility improving in the top two accessibility quintiles while declining in the bottom two. Metro Charlotte saw relatively modest changes due to shifting employment locations over time, with some accessibility loss in the lowest accessibility quintile. Note that Charlotte's results would be quite different if employment growth were factored in as well as shifting employment locations.

The effect of changing employment locations on transit accessibility was more starkly contrasting. For metro Chicago, there were strong improvements in transit accessibility across the board. For metro St. Louis, there were strong decreases in transit accessibility across the board — indicating a significant spatial shift with jobs relocating toward transit-inaccessible locations. In Seattle, high-transit accessibility locations gained additional transit accessibility, while low-transit accessibility locations lost further ground. Changing employment locations had little effect on transit accessibility in Charlotte.

Table 9: Effect of changing employment locations on auto accessibility

\begin{tabular}{lcccc}
\hline $\begin{array}{l}\text { Percent Change in Auto Accessibility from } \mathbf{2 0 0 0} \text { to } \mathbf{2 0 1 0} \\
\text { Auto Accessibility Quintile }\end{array}$ & Charlotte & Chicago & St. Louis & Seattle \\
\hline Highest quintile & $0.4 \%$ & $4.4 \%$ & $-5.6 \%$ & $6.8 \%$ \\
2nd quintile & $1.9 \%$ & $3.1 \%$ & $-3.9 \%$ & $4.6 \%$ \\
3rd quintile & $0.1 \%$ & $1.0 \%$ & $-1.9 \%$ & $-2.1 \%$ \\
4th quintile & $-0.6 \%$ & $3.1 \%$ & $3.4 \%$ & $-5.5 \%$ \\
Lowest quintile & $-3.2 \%$ & $3.0 \%$ & $4.7 \%$ & $-9.5 \%$ \\
\hline
\end{tabular}

Note: This table shows the percentage change in auto accessibility if employment locations are shifted while holding employment totals constant. Employment locations are shifted from their year 2000 locations to their year 2010 locations. In addition, travel times and residential locations are held at their year 2000 levels. TAZs are sorted by auto accessibility and grouped into five equal population quintiles. Auto accessibility is summed for each group, weighting each TAZ by its 2000 population.

Table 10: Effect of changing employment locations on transit accessibility

\begin{tabular}{lcccc}
\hline $\begin{array}{l}\text { Percent Change in Transit Accessibility from } \mathbf{2 0 0 0} \text { to } 2010 \\
\text { Transit Accessibility Tercile }\end{array}$ & Charlotte & Chicago & St. Louis & Seattle \\
\hline Highest tercile & $1.3 \%$ & $25.9 \%$ & $-9.6 \%$ & $9.5 \%$ \\
Middle tercile & $-2.4 \%$ & $15.8 \%$ & $-8.5 \%$ & $-3.6 \%$ \\
Lowest tercile & $4.5 \%$ & $14.6 \%$ & $-12.3 \%$ & $-14.4 \%$ \\
\hline
\end{tabular}

Note: This table shows the percentage change in transit accessibility if employment locations are shifted while holding employment totals constant. Employment locations are shifted from their year 2000 locations to their year 2010 locations. In addition, travel times and residential locations are held at their year 2000 levels. TAZs are sorted by transit accessibility and grouped into three equal population terciles. Transit accessibility is summed for each group, weighting each TAZ by its 2000 population. 


\subsection{Effect of changing travel times}

Most of the populations of Charlotte, Chicago, and St. Louis experienced improving auto travel times for most of their population. Table 11 displays what percentage of the population in each metro area that saw accessibility improvements or losses due to changing auto travel speeds. It is interesting that such benefits were unevenly distributed, with a fair share of the populations of Charlotte, Chicago, and St. Louis losing at least some accessibility due to slower auto travel times. Most Seattleites underwent slower travel times and decreasing auto accessibility of about $0-5$ percent, but 14.2 percent experienced a drop of 10 percent or more in auto accessibility due to speed changes during this period.

Table 12 shows transit accessibility gains and losses across the population due to transit speeds for each metro. Transit accessibility gains and losses were much more concentrated, likely due to transit's more localized service area. Large percentages of Charlotte's, Chicago's, and Seattle's populations saw a big jump in transit accessibility due to higher transit level of service. However, in Charlotte and Chicago, about one-third of the population also experienced big decreases of 15 percent or more in transit access due to changing transit service. As noted before, nearly the entire population of St. Louis saw major decreases in transit accessibility due to lower transit levels of service.

Table 12: Distribution of accessibility change due to transit travel times

\begin{tabular}{|c|c|c|c|c|}
\hline \multicolumn{5}{|c|}{ Percent of the Population Experiencing Accessibility Change Magnitudes due to Changing Transit Travel Speeds } \\
\hline Accessibility Change & Charlotte & Chicago & St. Louis & Seattle \\
\hline Above $15 \%$ & $45.9 \%$ & $19.0 \%$ & $3.3 \%$ & $34.1 \%$ \\
\hline 10 to $15 \%$ & $1.5 \%$ & $4.0 \%$ & $0.5 \%$ & $11.9 \%$ \\
\hline 5 to $10 \%$ & $5.1 \%$ & $6.4 \%$ & $0.4 \%$ & $18.7 \%$ \\
\hline 0 to $5 \%$ & $4.0 \%$ & $7.8 \%$ & $0.3 \%$ & $26.4 \%$ \\
\hline 0 to $-5 \%$ & $1.9 \%$ & $8.9 \%$ & $0.1 \%$ & $5.4 \%$ \\
\hline-5 to $-10 \%$ & $2.6 \%$ & $7.9 \%$ & $0.3 \%$ & $1.9 \%$ \\
\hline-10 to $-15 \%$ & $5.1 \%$ & $9.6 \%$ & $0.8 \%$ & $0.6 \%$ \\
\hline Below $-15 \%$ & $33.8 \%$ & $36.4 \%$ & $94.3 \%$ & $1.0 \%$ \\
\hline
\end{tabular}

Note: For this table, TAZ-to-TAZ travel speeds are permitted to vary from their 2000 to their 2010 levels, while both residential locations and employment locations are held constant. A new gravity accessibility score is calculated for the year 2010 and compared to year 2000 for the same TAZ as a baseline. The household counts are assigned to each TAZ and household distributions are calculated.

In addition to the overall distribution of travel time changes, the spatial location of these changes is also of interest. Table 13 highlights how auto speed improvements to accessibility vary by household density. Chicago and St. Louis offer a stark contrast (See Table 13). Chicago's improvements to auto travel times are heavily centralized, focused on where most of the current population is. That is, Chicago's investments in auto infrastructure primarily benefit those locations where residents are concentrated. St. Louis, on the other hand, shows no distinction between high- and low-density locations. St. Louis' transportation improvements effectively serve locations with undeveloped land as much as they serve existing concentrations of population.

Another interesting contrast is between Seattle and Charlotte. Seattle experienced poorer auto speeds across all five density quintiles, but the greatest losses were in the lower-density areas, with relatively small losses in the top two quintiles of household density. Charlotte's auto accessibility improved most in its two lowest density quintiles, again increasing accessibility for mostly undeveloped land rather than focusing its accessibility increases on where most of the current population is. This point is further illustrated by Table 15, which shows significant positive correlations of auto travel-speed changes with household density in Chicago and Seattle and significant negative correlations in Charlotte and St. Louis. 
Changes to transit accessibility also vary by levels of household density, as illustrated in Table 14 . In Charlotte, transit service increases across all levels of household density, but to the greatest degree in the lower-density areas. On the other hand, in Chicago transit service declines nearly everywhere, with the largest decreases in its highest density areas. St. Louis experienced transit level of service decreases across the board. Improvements to transit in Seattle were fairly uniform across TAZs without respect to household density.

Table 13: Accessibility change due to auto speeds by household density

\begin{tabular}{lcccc}
\hline $\begin{array}{l}\text { Percent Change in Auto Accessibility from } \mathbf{2 0 0 0} \text { to } 2010 \\
\text { Quintiles of Household Density }\end{array}$ & Charlotte & Chicago & St. Louis & Seattle \\
\hline Highest quintile & $-1.4 \%$ & $24.3 \%$ & $2.6 \%$ & $-1.7 \%$ \\
2nd quintile & $5.0 \%$ & $21.7 \%$ & $4.2 \%$ & $-3.1 \%$ \\
3rd quintile & $10.2 \%$ & $10.1 \%$ & $8.1 \%$ & $-4.1 \%$ \\
4th quintile & $13.4 \%$ & $7.7 \%$ & $5.4 \%$ & $-4.0 \%$ \\
Lowest quintile & $12.9 \%$ & $-2.3 \%$ & $4.0 \%$ & $-5.3 \%$ \\
\hline
\end{tabular}

Notes: Auto accessibility for each TAZ is calculated for 2010 and for 2000 using different travel times. A percent change is calculated for each TAZ, and then TAZs are aggregated by weighting the number of households in each TAZ in 2000. Quintiles are formed by sorting TAZs by gross household density, dividing TAZs into five equally sized population groups, and weighting each TAZ's accessibility by its 2000 population. Percent change is the total sum auto accessibility for each group.

Table 14: Accessibility change due to transit speeds by household density

Percent Change in Transit Accessibility from 2000 to 2010

\begin{tabular}{lcccc} 
Quintiles of Household Density & Charlotte & Chicago & St. Louis & Seattle \\
\hline Highest quintile & $4.9 \%$ & $-16.3 \%$ & $-57.9 \%$ & $8.4 \%$ \\
2nd quintile & $5.0 \%$ & $-11.8 \%$ & $-61.7 \%$ & $13.4 \%$ \\
3rd quintile & $25.9 \%$ & $-7.3 \%$ & $-62.0 \%$ & $12.4 \%$ \\
4th quintile & $4.9 \%$ & $-2.7 \%$ & $-59.6 \%$ & $11.1 \%$ \\
Lowest quintile & $59.8 \%$ & $1.5 \%$ & $-60.7 \%$ & $9.6 \%$ \\
\hline
\end{tabular}

Note: Transit accessibility for each TAZ is calculated for 2010 and for 2000 using different travel times. TAZs with zero transit accessibility in 2000 are excluded. Quintiles are formed by sorting TAZs by gross household density, dividing TAZs into five equally sized population groups, and weighting each TAZ's accessibility by its 2000 population. Percent change is the total sum transit accessibility for each group.

Table 15: Correlation between 2000 household density and auto speed improvement

\begin{tabular}{lcccc}
\hline & Charlotte & Chicago & St. Louis & Seattle \\
\hline Correlation & -0.201 & 0.351 & -0.090 & 0.222 \\
T statistic & -11.111 & 16.521 & -4.557 & 6.958 \\
P statistic & 0.000 & 0.000 & 0.000 & 0.018 \\
N & 2932 & 1942 & 2525 & 936 \\
\hline
\end{tabular}

Note: Unit of analysis is the traffic analysis zone. Correlation of household density. 
Figures 3 and 4, following, illustrate spatial differences in the influence of changing auto speeds on accessibility, and Figures 5 and 6 illustrate spatial differences of transit speeds on accessibility, respectively. Very different patterns of spatial benefit are visible across metros. In Charlotte and St. Louis, improvements to auto speeds primarily benefited the outlying regions, with the very edge of the St. Louis region benefiting most from faster auto speeds. Meanwhile, in Seattle and Chicago, the benefits were skewed toward the central parts of the region. To be more precise, the central parts of Chicago saw substantial improvements to auto speeds, whereas in Seattle, the central parts of the region experienced a lower decline in auto speeds relative to the outlying parts of the region.

Transit speeds influenced accessibility also in distinctive ways. Charlotte experienced strong transit accessibility improvements along certain corridors, while also seeing decreased transit accessibility in areas between these corridors. In a similar pattern, St. Louis saw improvements to a few TAZs along its light rail line, but very large decreases in transit accessibility elsewhere. Chicago underwent a broad boost to transit accessibility across its suburban and exurban areas while also seeing some loss in transit accessibility in more central parts of the region. Large parts of the Seattle region experienced improving transit accessibility, with the greatest improvements toward the center of the region. 


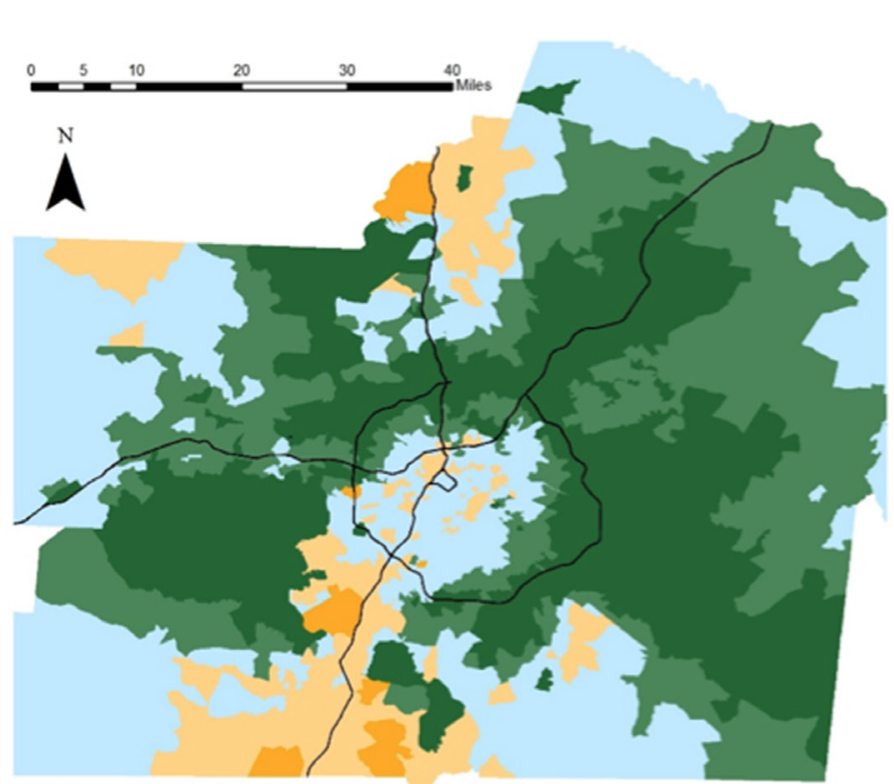

Auto Accessibility Change due to Speeds, 2000-2010

$15 \%$ decrease or worse 5 - $15 \%$ decrease

little change

$5-15 \%$ increase

$15 \%$ increase or greater

\section{CHARLOTTE}

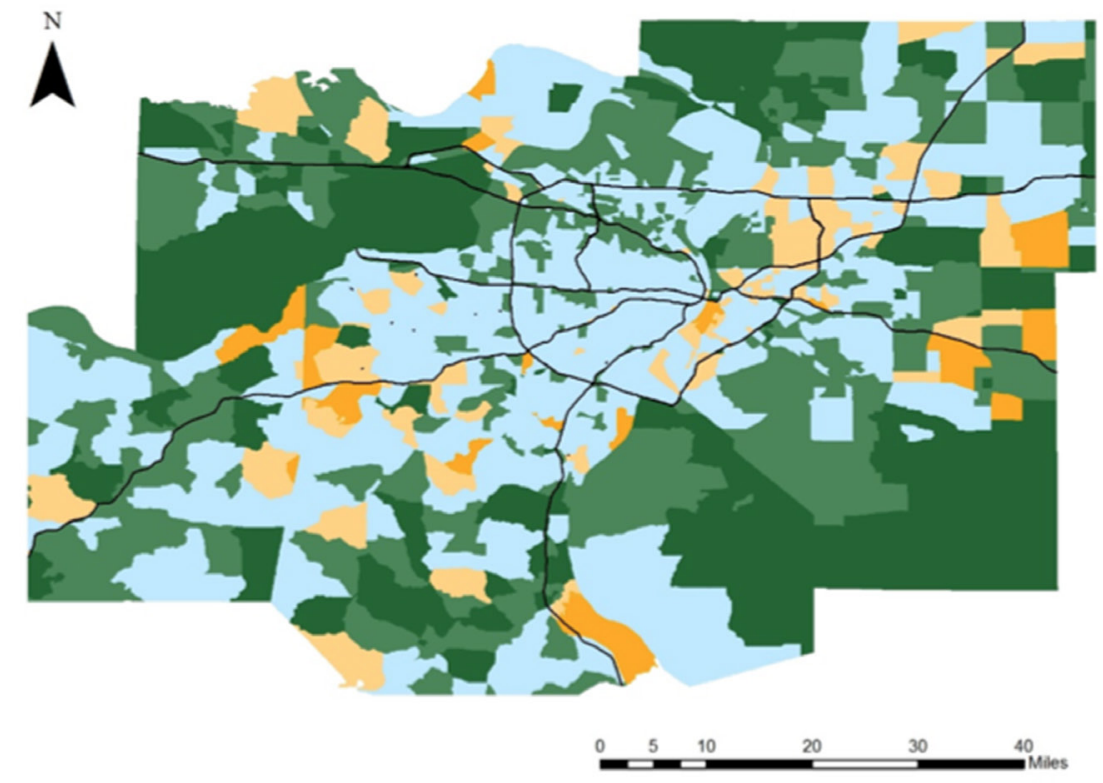

ST LOUIS

Figure 2: Maps of accessibility change due to auto speed changes for Charlotte and St. Louis 


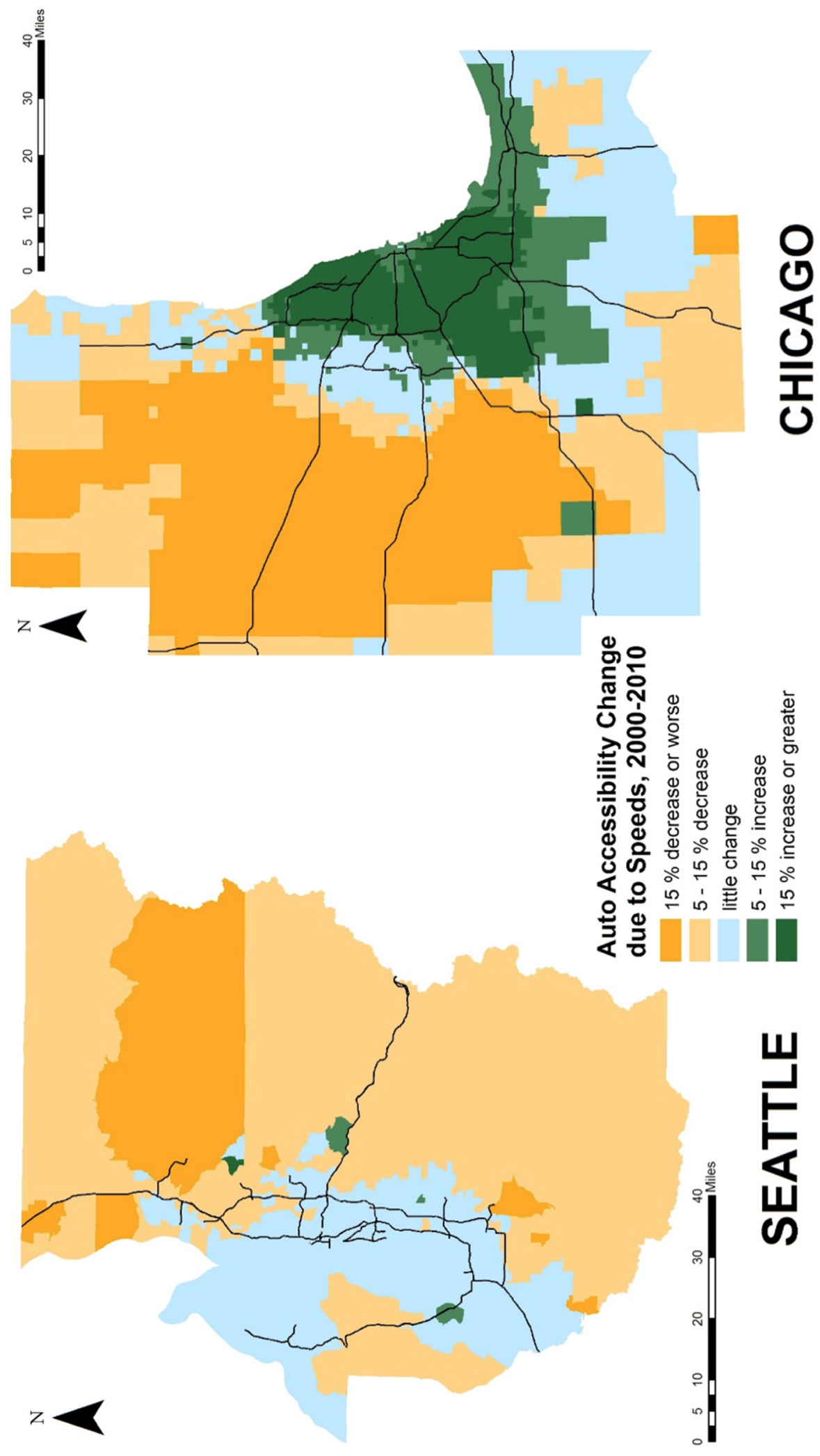




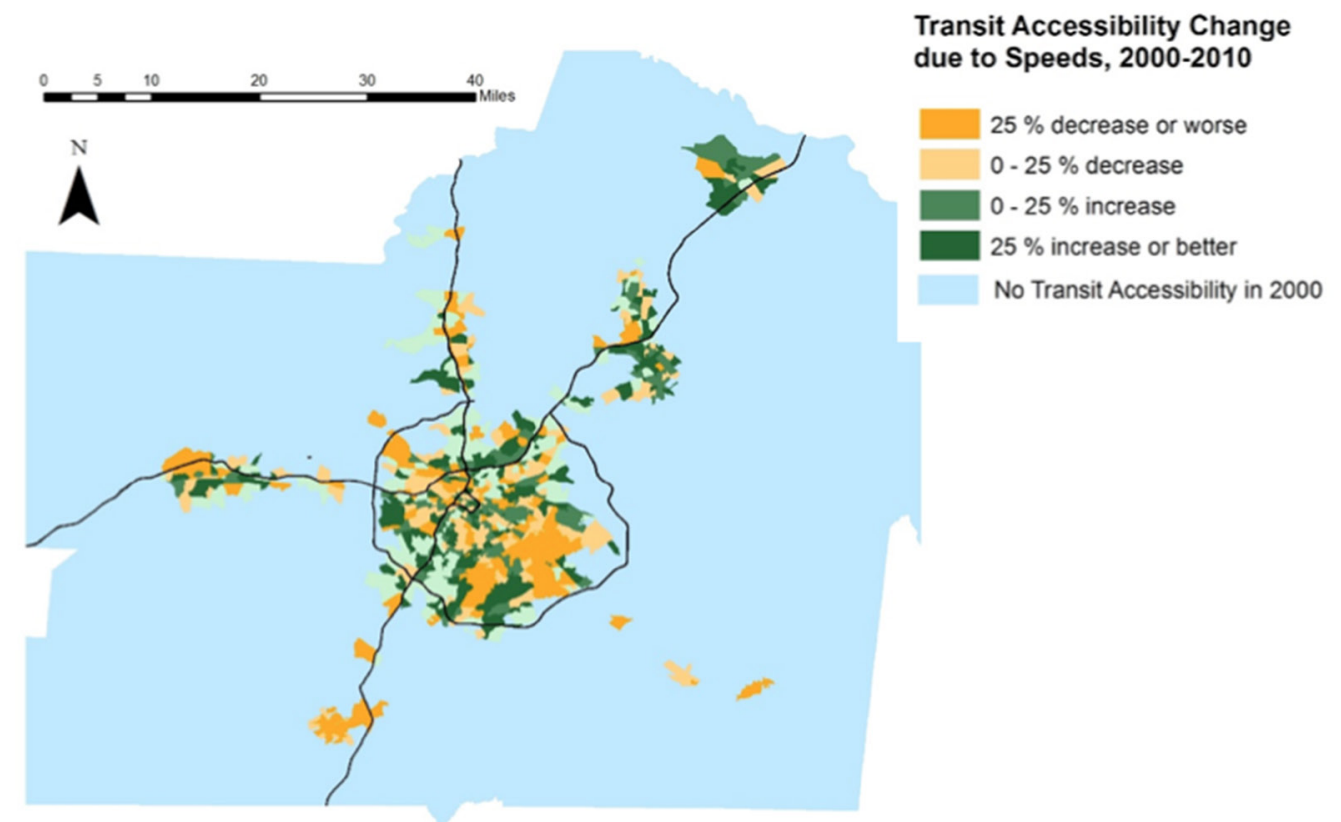

CHARLOTTE

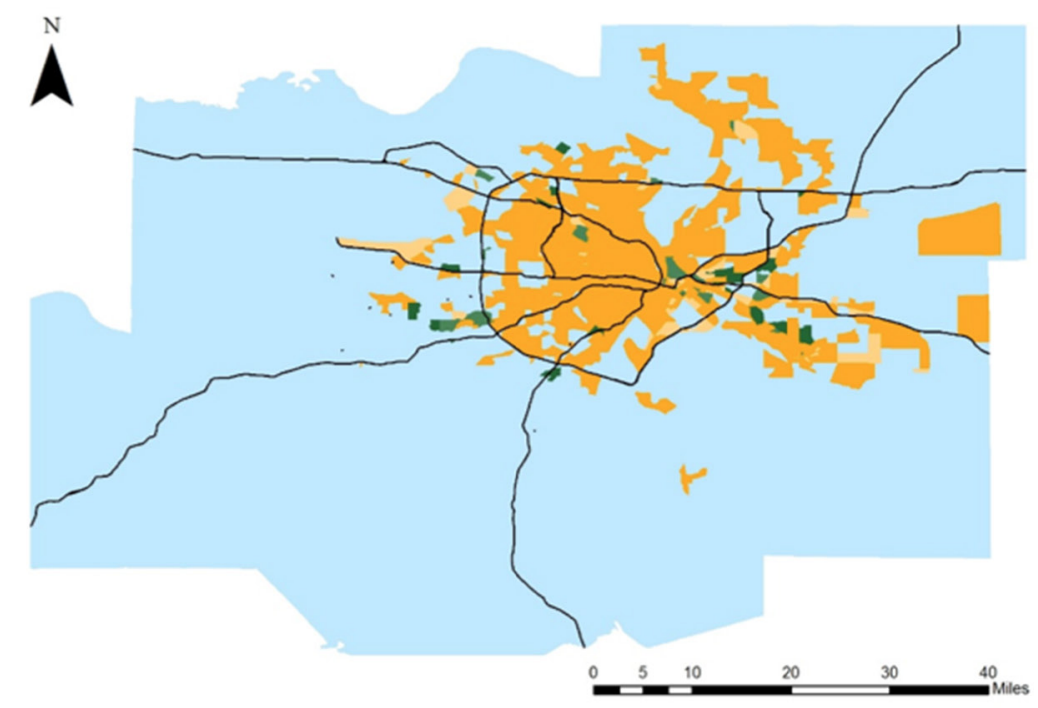

ST LOUIS

Figure 4: Maps of accessibility change due to transit speed changes for Charlotte and St. Louis 

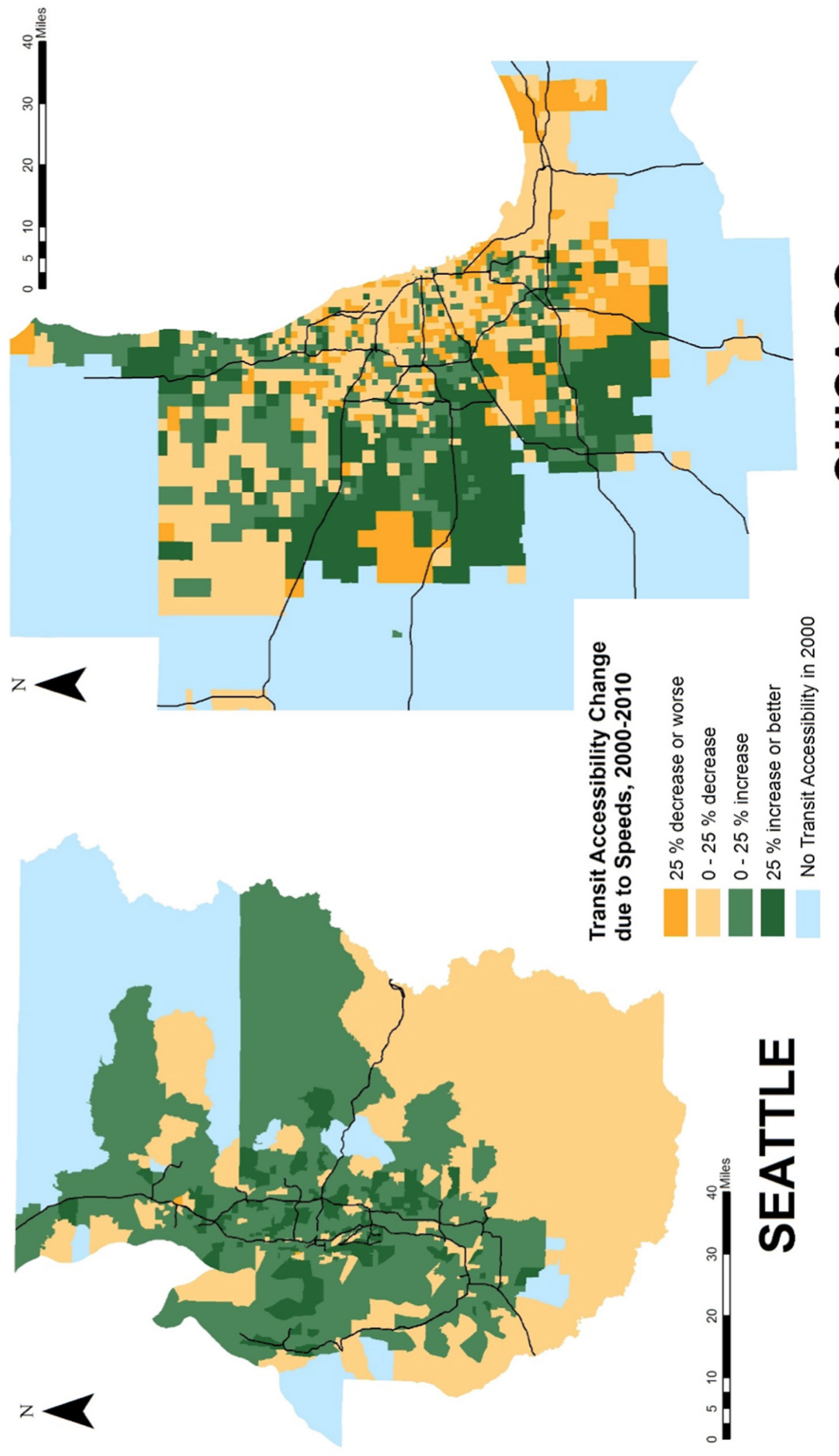

$\frac{0}{0}$
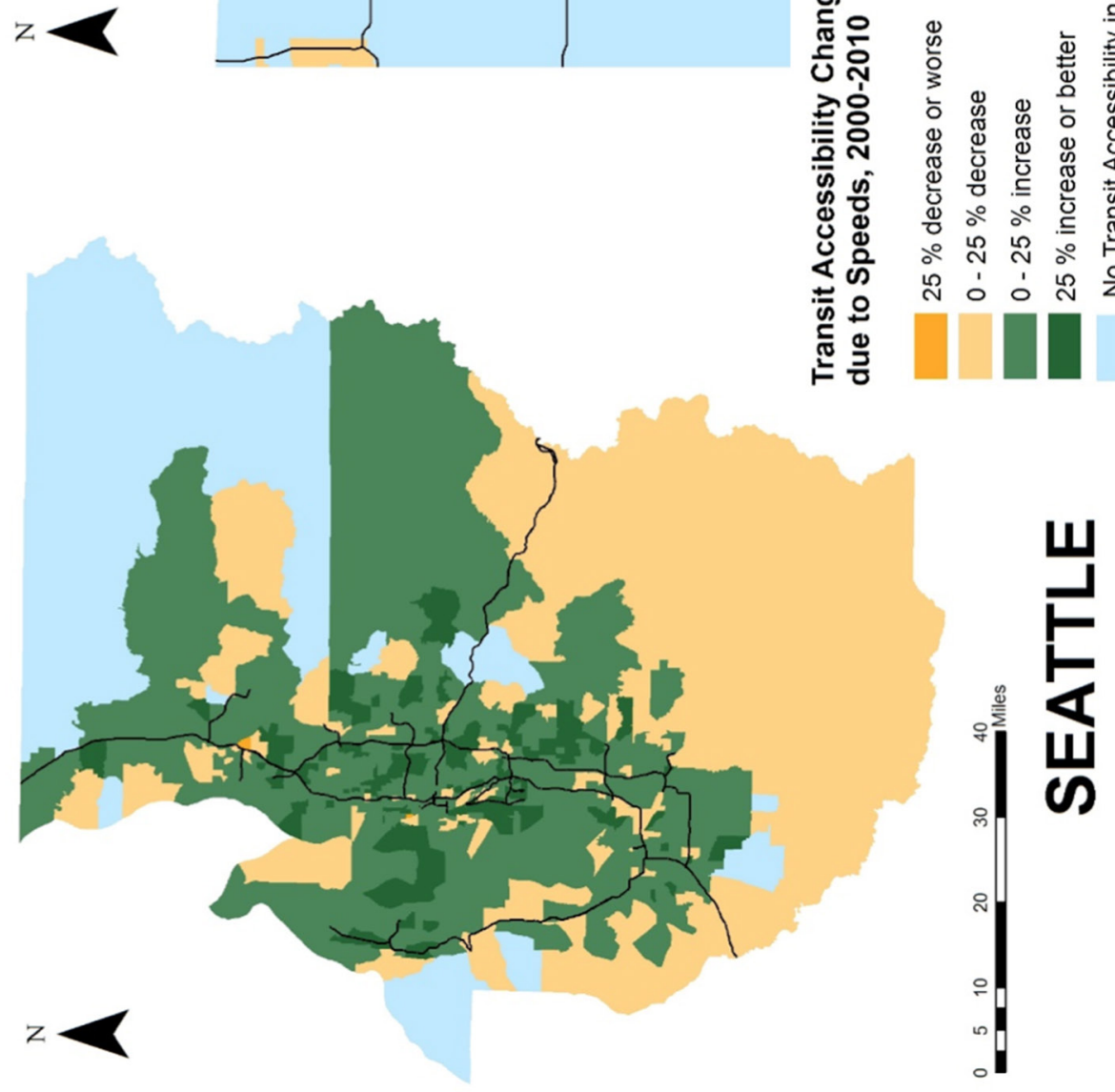


\section{Discussion}

Metropolitan accessibility change over time is influenced both by the location of new development and by changes to transportation patterns. Therefore, tracking accessibility change over time as a performance measure yields unique insights into the coordination of land-use and transportation patterns at the regional scale.

In three of the four metro areas studied, the location of new residential development was negatively correlated with auto accessibility scores. This suggests that new development in many metropolitan areas is predominantly shifting toward lower accessibility locations, reducing average household accessibility over time. Similar patterns were observed with respect to new development and transit accessibility, where the highest rates of household growth were in areas with no transit provision, and the lowest rates of growth were in the top transit accessibility areas (See Table 7).

This regional view offers a new and somewhat more pessimistic view of transit-oriented development trends. Transit accessibility did improve for the most transit-accessible parts of the region in Charlotte, Chicago, and Seattle over the study period. This provides at least a partial validation for metro Charlotte's transit-oriented development program, which by most reports has been highly successful (Newsom and Gallagher 2014). Certainly many more people in the Charlotte region had better access to high-quality transit in 2010 than in 2000. Nevertheless, from a regional perspective, far more residential growth occurred in low transit-accessibility areas than in high transit-accessibility areas in metropolitan Charlotte (See Table 7). This explains why transit accessibility for metropolitan Charlotte did not improve for much of the rest of the population (about 85 percent of the total), despite major investment in transit infrastructure (Table 4).

Metropolitan employment decentralization has often been argued to be beneficial, because it increases the accessibility to employment of an already decentralized population (Giuliano and Small 1993; Glaeser and Kahn 2003). Metropolitan St. Louis displays this pattern, with shifting employment patterns increasing accessibility for low-density areas while decreasing accessibility for high-density areas (See Table 9). However, such employment decentralization can decrease employment accessibility for those who are transit-dependent, which is also borne out in the numbers for St. Louis (See Table 10). Chicago, on the other hand, shifted employment toward transit-accessible locations, and saw improvements to both auto and transit accessibility for high- and low-density parts of the metro region (See Table 9 and Table 10). So it is not necessarily the case that employment shifts result in a zero-sum gain across the region. It appears that balanced shifts to employment location, such as those experienced by the Chicago region, have the potential to provide widespread accessibility benefits.

Changes to auto and transit level of service, reflected in changing travel speeds, are the product of many factors, including new infrastructure, changes to levels of transit provision, and shifting levels of congestion. Although I cannot tease out the various causes of changes to travel times here, there are clear and important implications to differing spatial priorities for transportation improvements. Examining the travel-speed changes for Chicago and St. Louis, both slow growing and older metros, presents a major difference in spatial priorities. Speed improvements in the Chicago region were concentrated where existing residents reside and were positively correlated with household density. Speed improvements in the St. Louis region were concentrated in low-density parts of the region, which are largely comprised of undeveloped land. The result of the Chicago region's priorities are likely to be better accessibility by automobile for many current residents. The result of the St. Louis region's priorities are likely to be continued decentralization of the region as new development takes advantage of the improved accessibility provided to undeveloped and outlying parts of the region. 


\subsection{Study limitations}

While the TAZ-level of geography provides valuable insights into regional variations in accessibility patterns, the traffic analysis zone scale also homogenizes important intra-TAZ variations in accessibility. The accessibility to transit by walking varies depending on the street network and residential settlement patterns within each TAZ, a level of detail not captured here.

Accessibility to employment is a broad proxy for access to opportunities across the urban environment. This has sometimes been used in research as a measure for generalized access to urban opportunities (Helling 1998; Ahlfeldt 2011). More specific flavors of accessibility—accessibility to schools, to parks, to healthful food - may be of particular significance for more targeted policy analysis.

Equity analysis is a particularly important component of accessibility analysis and the analysis of accessibility change over time (Foth, Manaugh, El-Geneidy 2013; Grengs 2004). This paper analyzes changes to accessibility for the aggregate population, and therefore may miss important trends among specific population segments, in particular low-income or transit-dependent populations.

The impedance coefficient for travel time is here estimated based on metropolitan population size alone. Within gravity-based travel models, travel impedance is usually calibrated based on available travel survey data. Calibration certainly improves the behavioral predictability of gravity-based destination choice models, but such a level of precision is not necessary for this broad-stroke analysis of the geography of longitudinal accessibility change. See the Appendix for a further discussion of this claim.

In addition to gravity or potential accessibility, many other accessibility measures are possible and may reveal different insights about spatial interaction at different scales or for different purposes. Here a single potential accessibility measure is analyzed for the purposes of succinct communication of complex results, i.e., changes over two periods of time for two modes for four metropolitan areas and thousands of transportation analysis zones within each metro.

Furthermore, the time period under analysis, 2000 to 2010, is unusual in a number of respects, notably the major recession that occurred in the United States during the end of the 2000s. This recession particularly affected the housing market, depressing the construction of new housing. Therefore, the amount of change to urban form during this time period may be less than would be experienced in other 10 -year time periods.

\section{Conclusion}

This paper examines changes in the ability of urban form to provide accessibility to employment locations by auto and transit modes for four metropolitan areas, Charlotte, Chicago, Seattle, and St. Louis, over the 2000 to 2010 period. This is the first paper to examine longitudinal change in metropolitan accessibility at a detailed scale (i.e., using TAZ-level geography) using similar methods across multiple metropolitan areas.

Three distinct influences on accessibility change are identified and isolated for analysis: shifting household locations, shifting employment locations, and changing travel speeds. In most cases, household growth was fastest in parts of these regions with lower auto and lower transit accessibility. The exception to this rule was fast-growing metro Charlotte, where household growth occurred approximately equally in high- and low-accessibility parts of the region. Shifting employment locations benefited primarily lower-accessibility locations in some metros (St. Louis), but in other metros, shifting employment locations provided benefits across the board (Chicago).

Changing travel speeds also had distinctive spatial patterns across the metros. Some metro areas experienced the greatest speed improvements in parts of the metro region where people are concentrated (Chicago, Seattle), while others underwent the greatest speed improvements in predominantly 
undeveloped areas (Charlotte, St. Louis). Focusing the benefits of transportation improvements toward undeveloped areas may incidentally promote sprawling development patterns.

Coordinating regional growth patterns and transportation investments to increase accessibility for a broad swath of the population is a major planning challenge. Analyzing accessibility change over time allows us to understand more deeply the consequences of the land-use and transportation changes metropolitan regions experience. For metropolitan regions to foster widespread improvements to accessibility, they should pursue three objectives simultaneously. First, new residential development should be channeled predominantly toward high-accessibility parts of the metropolitan region. Second, new employment must be located strategically across the region to increase transit accessibility and auto accessibility for residents in both outlying and central residential areas. And third, transportation infrastructure and service improvements should focus the lion's share of benefits where there are existing urban populations, rather than providing greater accessibility predominantly to undeveloped and outlying areas. Taken together, these three strategies offer a promising template for improving household accessibility over time across major metropolitan areas. With improvements to household accessibility across the region, the accompanying benefits of greater economic and social opportunities for households and reduced travel demand should follow.

\section{Acknowledgements}

Thanks to the many colleagues who provided helpful feedback as this article was under development, including Jonathan Levine, Kevin Manaugh, Noreen McDonald, Daniel Rodriguez, and Yan Song. I also want to express thanks for the many travel-demand modelers who helped provide data for this project at the Chicago Metropolitan Agency for Planning, Puget Sound Regional Council, East-West Council of Governments, and the city of Charlotte. Finally, without the crucial financial support of the Royster Society of Fellows and the Dow Sustainability Postdoctoral Fellowship, this work would not have been possible. Thanks to all who generously fund academic research. 


\section{References}

Ahlfeldt, G. 2011. If Alonso was right: Modeling accessibliity and explaining the residential land gradient. Journal of Regional Science 51:318-338. http://dx.doi.org/10.1111/j.1467-9787.2010.00694.x.

Axhausen, K. W. 2008. Accessibility long-term perspectives. Journal of Transport and Land Use 1(2): 5-22. https://www.jtlu.org/index.php/jtlu/article/view/66.

Axhausen, K. W., P. Froelich, and M. Tschopp. 2011. Changes in Swiss accessibility since 1850. Research in Transportation Economics 31(1): 72-80. http://linkinghub.elsevier.com/retrieve/pii/ S0739885910001320.

Bertolini, L., F. le Clercq, and L. Kapoen. 2005. Sustainable accessibility: A conceptual framework to integrate transport and land use plan-making. Two test-applications in the Netherlands and a reflection on the way forward. Transport Policy 12(3): 207-220.

Bhat, C. L., K. Kockelman, Q. Chen, S. Handy, H. Mahmassani, and L. Weston. 2000. Development of an Urban Accessibility Index: Literature Review. Austin, TX: University of Texas, Center for Transportation Research. http://www.utexas.edu/research/ctr/pdf_reports/4938_1.pdf.

Bunel, M., and E. Tovar. 2014. Key issues in local job accessibility measurement: Different models mean different results. Urban Studies 51: 1322-1338. http://usj.sagepub.com/content/51/6/1322. abstract.

Bureau of Transportation Statistics. 2004. Census Transportation Planning Package 2000, Part 2: Place of Work. Washington, DC: US Bureau of Transportation Statistics.

Cervero, R. 1996. Paradigm Shift: From Automobility to Accessibilty Planning. Berkeley, CA: Institute for Urban and Regional Development.

Cervero, R., T. Rood, and B. Appleyard. 1999. Tracking accessibility: Employment and housing opportunties in the San Francisco Bay Area. Environment and Planning A 31:1259-1278.

Cervero, R., and K. L. Wu. 1998. Subcentering and commuting: Evidence from the San Francisco Bay Area 1980-1990. Urban Studies 35: 1059-1076.

Chen, S., C. Claramunt, and C. Ray. 2014. A spatio-temporal modelling approach for the study of the connectivity and accessibility of the Guangzhou metropolitan network. Journal of Transport Geography 36: 12-23.

Chicago Area Transportation Study, 2000. Destination 2020: 2020 regional transportation plan, 2000 Edition. Chicago, IL: Chicago Area Transportation Study.

Chicago Metropolitan Agency for Planning, 2010. Go To 2040 comprehensive regional plan-draft. Chicago, IL: Chicago Metropolitan Agency for Planning.

Curtis, C. 2011. Integrating land use with public transport: The use of a discursive accessibility tool to inform metropolitan spatial planning in Perth. Transport reviews 31(2): 179-197.

East West Gateway Coordinating Council. 2002. Legacy 2025: The Transportation Plan for the Gateway Region. St. Louis, MO: East West Gateway Coordinating Council.

ESPON 2020 Program, 2013. Transport Accessibility at Regional/Local Scale and Patterns in Europe. Luxembourg, Germany: ESPON 2020 Program.

Ewing, R., and R. Cervero. 2010. Travel and the built environment-a meta-analysis. Journal of the American Planning Association 76: 265-294.

Fan, Y., A. E. Guthrie, and D. M. Levinson. 2012. Impact of light rail implementation on labor market accessibility: A transportation equity perspective. Journal of Transport and Land Use 5(3): 28-39. https:/www.jtlu.org/index.php/jtlu/article/view/240.

Foth, N., K. Manaugh, and A. M. El-Geneidy. 2013. Towards equitable transit: Examining transit accessibility and social need in Toronto, Canada, 1996-2006. Journal of Transport Geography 29: 1-10. 
Geurs, K., and J. R. Ritsema van Eck. 2003. Evaluation of accessibility impacts of land-use scenarios: The implications of job competition, land-use, and infrastructure developments for the Netherlands. Environment and Planning B: Planning and Design 30(1): 69-87.

Geurs, K., and B. Van Wee. 2004. Accessibility evaluation of land-use and transportation strategies: Review and research directions. Journal of Transport Geography 12: 127-140.

Giuliano, G., and K. A. Small. 1993. Is the journey to work explained by urban structure? Urban Studies 30: $1485-1500$.

Giuliano, G., and K. A. Small. 1991. Subcenters in the Los Angeles region. Regional Science and Urban Economics 21: 163-182.

Glaeser, E. L., and M. E. Kahn. 2003. Sprawl and urban growth, in Handbook of Regional and Urban Economics, edited by J. V. Henderson and J.-F. Thisse. Cambridge, MA: National Bureau of Economic Research. URL: http://www.nber.org/papers/w9733.pdf.

Grengs, J., J. Levine, Q. Shen, and Q. Shen. 2010. Intermetropolitan comparison transportation accessibility: Sorting out mobility and proximity in San Fransico and Washington DC. Journal of Planning Education and Research 29: 427-443.

Grengs, J. 2004. Measuring change in small-scale transit accessibility with geographic information systems-Buffalo and Rochester, New York. Transportation Research Record 1887: 10-17.

Gutierrez, J., A. Condeco-Melhorado, and J. Carlos Martin. 2010. Using accessibility indicators and GIS to assess spatial spillovers of transport infrastructure investment. Journal of Transport Geography 18(1): 141-152.

Handy, S. L., and D. A. Niemeier. 1997. Measuring accessibility: An exploration of issues and alternatives. Environment and Planning A 29: 1175-1194.

Helling, A. 1998. Changing intra-metropolitan accessibility in the US: Evidence from Atlanta. Progress in Planning 49: 55-103.

Holl, A. 2007. Twenty years of accessibility improvements. The case of the Spanish motorway building program. Journal of Transport Geography 15(4): 286-297.

Hou, Q., and S.-M. Li. 2011. Transport infrastructure development and changing spatial accessibility in the Greater Pearl River Delta, China, 1990-2020. Journal of Transport Geography 19(6): 1350-1360.

Kim, H., and S. Sultana. 2015. The impacts of high-speed rail extensions on accessibility and spatial equity changes in South Korea from 2004 to 2018. Journal of Transport Geography 45: 48-61.

Krizek, K. J. 2003. Neighborhood services, trip purpose, and tour-based travel. Transportation 30: 387410.

Levine, J., J. Grengs, Q. Shen, and Q Shen. 2012. Does accessibility require density or speed? Journal of the American Planning Association 78: 157-172.

Levine, J., J. Grengs, and Q. Shen. 2010. The demographics of transportation accessibility: An intermetropolitan comparison. Transed 2010: 12th International Conference on Mobility and Transport for Elderly and Disabled Persons, June 2-4, Hong Kong, China.

Levinson, D. M. 2013. Access Across America. Minneapolis, MN: University of Minnesota, Center for Transportation Studies.

Levinson, D. M. 1998. Accessibility and the journey to work. Journal of Transport Geography 6(1): $11-21$.

Levinson, D. M., and B. Marion. 2010. The City is Flatter: Changing Patterns of Job and Labor Access in Minneapolis-Saint Paul, 1995-2005. No 000077, Working Papers. University of Minnesota: Nexus Research Group. http://EconPapers.repec.org/RePEc:nex:wpaper:thecityisflat.

Martinez Sanchez-Mateos, H. S., I. M. Sanz, J. M. Ureña Francés, and E. S. Trapero. 2014. Road accessibility and articulation of metropolitan spatial structures: The case of Madrid (Spain). Journal of 
Transport Geography 37: 61-73.

Mecklenberg/Union Technical Cooridnating Committeee, 2002. 2025 Long Range Transportation Plan. Charlotte, NC: Mecklenburg/Union Metropolitan Planning Organization.

Merlin, L. A. 2014. Measuring community completeness: Jobs-housing balance, accessibility, and convenient local access to nonwork destinations. Environment and Planning B: Planning and Design 41: 736-756. http://www.envplan.com/abstract.cgi?id=b120010p.

Miller, H. J. 1999. Measuring space-time accessibility benefits within transportation networks: Basic theory and computational procedures. Geographical Analysis 31: 1.

Neutens, T., M. Delafontaine, T. Schwanen, and N. Van de Weghe. 2012. The relationship between opening hours and accessibility of public service delivery. Journal of Transport Geography 25: 128140.

Newsom, M., and D. R. Gallagher. 2014. What comes first in TOD? American Planning Association National Planning Conference, April 25-30, Atlanta, GA.

Owen, A., and D. M. Levinson. 2015. Modeling the commute mode share of transit using continuous accessibility to jobs. Transportation Research Part A: Policy and Practice 74: 110-122. http://linkinghub.elsevier.com/retrieve/pii/S0965856415000191.

Puget Sound Regional Council. 2008. Vision 2040 draft environmental impact statement. Seattle, WA: Puget Sound Regional Council.

Puget Sound Regional Council and Council, P.S.R. 2001. Destination 2030: Metropolitan transportation plan for the central Puget Sound region. Seattle, WA: Puget Sound Regional Council.

Reggiani, A., P. Bucci, and G. Russo. 2011. Accessibility and impedance forms: Empirical applications to the German commuting network. International Regional Science Review 34(2): 230-252.

Rosik, P., M. Stepniak, and T. Komornicki. 2015. The decade of the big push to roads in Poland: Impact on improvement in accessibility and territorial cohesion from a policy perspective. Transport Policy 37: 134-146.

Shaw, S.-L., Z. Fang, S. Lu, and R. Tao. 2014. Impacts of high speed rail on railroad network accessibility in China. Journal of Transport Geography 40(SI): 112-122.

Shrank, D., T. Lomax, and B. Eisele. 2011. 2011 Urban mobility report. College Station, TX: Texas Transportation Institute.

Srour, I. M., K. M. Kockelman, and T. P. Dunn. 2002. Accessibility indices: Connection to residential alnd prices and location choices. Transportation Research Record 1805: 25-34.

Stepniak, M., and P. Rosik. 2013. Accessibility improvement, territorial cohesion and spillovers: A multidimensional evaluation of two motorway sections in Poland. Journal of Transport Geography 31: 154-163.

Swanstorm, T., D. Kimball, T. Shrout, and L. Weidlocher. 2011. From checkbook campaigns to civic coalitions: Lessons from the Passage of Prop A. St. Louis, MO: University of Missouri, Public Policy Research Center.

Wang, J., F. Jin, H. Mo, and F. Wang. 2009. Spatioternporal evolution of China's railway network in the 20th century: An accessibility approach. Transportation Research Part A: Policy and Practice 43(8): 765-778.

Weitz, J. 2012. Growth management in the United States, 2000-2010: A decennial review and synthesis. Journal of Planning Literature 27: 394-433. http://jpl.sagepub.com/content/27/4/394.abstract.

Weitz, J., and T. Crawford. 2012. Where the jobs are going: Job sprawl in US metropolitan regions. Journal of the American Planning Association 78: 53-69. 


\section{Appendix A: Selecting an appropriate functional form and impedance for accessibility potential}

Although precision in the construction of accessibility metrics is preferable where feasible, there is strong evidence that various metro-scale accessibility measures are highly correlated regardless of the precise functional form or impedance coefficient specified. For example, Bunel and Tovar (2014, p.1330) found that the study's measures of local job accessibility for Paris-region municipalities are not particularly sensitive to the impedance coefficient used. Other research has also found considerable correlation between varying potential accessibility measures employing different functional forms (Reggiani, Bucci, and Rossi 2011, p. 240) and between constrained and unconstrained potential measures (Bunel and Tovar 2014, p. 1330; Geurs and Ritsema van Eck 2003, p. 81) as well as between work and non-work accessibility measures (Merlin 2014, p.11; Srour, Kockelman, and Dunn 2002, p. 32). Because spatial (employment-related) accessibility at the regional scale is largely a function of the locations of employment, which tend to be highly clustered at the metropolitan scale, many types of potential accessibility measures produce similar results despite differing functional forms or the specification of impedance coefficients.

With respect to the metro-specific impedance parameters used in this paper, I have conducted a sensitivity analysis to ensure that the results do not depend highly on precision with respect to the impedance parameter. The table below demonstrate that the accessibility scores of particular districts (TAZs) are highly correlated even if the estimated impedance coefficient is off by as much as 20 percent in either an upward or downward direction.

Table A-1: Sensitivity analysis of impedance coefficient

\begin{tabular}{lcccc}
\hline & Charlotte & Chicago & St. Louis & Seattle \\
\hline Original impedance coefficient & 0.103 & 0.078 & 0.100 & 0.097 \\
20\% larger impedance coefficient & 0.124 & 0.094 & 0.120 & 0.116 \\
20\% smaller impedance coefficient & 0.082 & 0.062 & 0.080 & 0.078 \\
& & & & \\
& & & \\
& Correlation of Accessibility & with Larger Impedance and Original Impedance \\
Auto accessibility 2000 & 0.997 & 0.991 & 0.997 & 0.995 \\
Auto accessibility 2010 & 0.997 & 0.990 & 0.998 & 0.995 \\
Transit accessibility 2000 & 0.993 & 0.991 & 0.996 & 0.995 \\
Transit accessibility 2010 & 0.993 & 0.990 & 0.996 & 0.995 \\
& & & & 0.997 \\
Auto accessibility 2000 & Correlation of Accessibility with Smaller Impedance and Original Impedance \\
Auto accessibility 2010 & 0.996 & 0.990 & 0.997 & 0.991 \\
Transit accessibility 2000 & 0.996 & 0.986 & 0.997 & 0.991 \\
Transit accessibility 2010 & 0.991 & 0.990 & 0.995 & 0.991 \\
\hline
\end{tabular}

